\title{
METAL MATERIALS AND SAFETY OF OLD BUILDINGS
}

\author{
Lajos György KOPENETZ11, Ferdinánd-Zsongor GOBESZ ${ }^{2}$ \\ Technical University of Cluj-Napoca, Faculty of Civil Engineering, Department of Structural Mechanics, \\ Cluj-Napoca, Romania \\ ${ }^{1}$ ludovic.kopenetz@mecon.utcluj.ro \\ 2go@mecon.utcluj.ro
}

\begin{abstract}
In case of old metal constructions, where the loadbearing structure dominates, material issues have a great influence on the behaviour of the construction both in terms of function and safety. Old metal constructions generally have a monumental nature, so preservation, restoration and rehabilitation works are inseparable from material issues. Due to this monumental nature, research into the material generally allows only minor damage, therefore these investigations require the use of special methods.
\end{abstract}

Keywords: structure, monument, safety, metals.

\section{Introduction}

The preservation, restoration and strengthening of old buildings requires not only structural analysis, but also adequate knowledge of the materials used. The most common problems are caused by natural aging.

It is known that protection against the corrosion in iron-based materials cannot be solved in old structures (among other recorded phenomena are issues such as bacteria digested tubes).

Compared with other buildings, these structures are characterized by greater slenderness and their loadbearing structure can cause many unexpected issues, so the various interventions must be carried out with much caution and great care.

It is generally accepted, that a loadbearing structure is safe if, after slightly displaced from its stable equilibrium state, it returns to its original state (where the potential energy of the system is the lowest). Without clarifying material issues, the stability and loadbearing requirements of these metallic structures do not necessarily provide safety for load cases that can cause complete failure or gradual collapse of the building. Only a small number of the typical mistakes made by safety assessing engineers is due to structural considerations, the biggest mistakes are related to improper knowledge of the materials.

\section{Material properties and tests}

During the study of old metallic structures it is very important to identify the nature and quality of the materials used [1, 2]. The metals are distinguished from other elements by their electrical conductivity and their metallic glaze. The research and testing of the materials used in old buildings is possible through archeometry, whereby the structural engineer can obtain the following information:

- The art-historical, archaeological, ethno-graphical aspects of the building and its building technique;

- The age and place of origin of the materials used;

- The relationship between the building and the development of the historical, social era.

The material quality tests can be carried out mainly by laboratory testing, but on-site examinations are also possible. The latter can be used to determine the magnitude of the deformations caused by the various loads, the dynamic characteristics of the structure and its response to dynamic loads (wind, various vibrations, resonance 
sensitivities), and to map perceivable damage, failures (through the use of magnetic crack detection, penetrating liquids, ultrasound, defectoscopy and inductive procedures). Based on laboratory testing it is possible to determine precisely the kind of materials (with, or recently even without sampling) and their physical properties (density, thermal conductivity, thermal expansion coefficient, melting point, elasticity coefficient, tensile strength, elongation at break, etc.), hardness, elastic or brittle behaviour.

In the structure of old metallic constructions (buildings, bridges, statues etc.) more frequently iron (Fe), copper $(\mathrm{Cu})$ and its alloys, zinc / spelter $(\mathrm{Zn})$, tin (Sn), lead (Pb), and occasionally silver $\mathrm{Ag})$, gold $\mathrm{(Au}$ ) can be found. Some characteristics of these metals are listed in Table 1.

\section{The more frequent metals used in old buildings}

We do not have the knowledge of our predecessors concerning metal-based materials; much of it is lost or outdated nowadays.

Gold has been used from the earliest times due to its low melting point. It was rarely used as a supporting structure, rather as a wire or covering (Figure 1.).

In ancient times, the structural gold wire was produced by twisting the flattened gold ribbons, and in the middle ages a forceps or pulling pin was used. The coverings were hammered out from gold plates.

Silver is a heavy, bright white metal, easily stretchable, relatively soft, hammerable material.

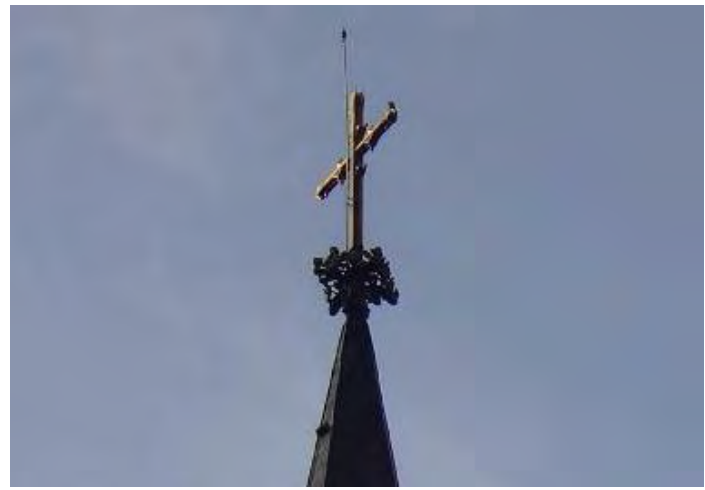

Figure 1. The nearly $4 \mathrm{~m}$ high gilded cross of the St. Michael's Church in Cluj-Napoca

Its casting was avoided because of the formation of a porous material. Its use in loadbearing structures is very rare, being used rather for alloying.

Copper is one of the oldest used metals, initially more commonly in forged shapes (different thickness plates). It is reddish, highly stretchable, and hammerable. In the presence of air a green layer (patina) is formed on its surface, which can stain the surrounding surfaces if it is dissolved by moisture. Due to the formation of a porous material, its casting was avoided (also because its melting point is rather high), but this issue could have been overcome by alloying. The brass (tompak, tombak) appeared in Roman times, combining copper and zinc (sometimes mixed with lead). It was used for molded pieces due to its lower melting point, but, of course, it has many applications in forged and cold-formed shapes too. Bronze is a mixture of copper and tin, widely used (e.g. lamp

Table 1. Physical properties and grouping of metals found in old structures

\begin{tabular}{|c|c|c|c|c|c|c|c|}
\hline $\begin{array}{c}\text { Characteristic } \\
\text { I metal }\end{array}$ & $\mathbf{P b}$ & Zn & Sn & $\mathrm{Cu}$ & $\mathrm{Au}$ & $\mathrm{Ag}$ & Fe \\
\hline \multicolumn{8}{|l|}{ Coloring } \\
\hline $\begin{array}{l}\text { Density } \\
(\text { daN/m³) }\end{array}$ & 11300 & 7140 & 7290 & 8860 & 19300 & 10500 & $7250-7800$ \\
\hline \multirow{2}{*}{$\begin{array}{l}\text { Melting point } \\
\left({ }^{\circ} \mathrm{C}\right)\end{array}$} & 327 & 419 & 232 & 1083 & 1063 & 960 & $1200-1350$ \\
\hline & & & & & & & \\
\hline $\begin{array}{l}\text { Thermal ex- } \\
\text { pansion factor } \\
\left(\times 10^{-6} / \text { grade }\right)\end{array}$ & 28.0 & 26.0 & 26.7 & 16.5 & 14.2 & 19.5 & $10.5-11.5$ \\
\hline $\begin{array}{c}\text { Elasticity fac- } \\
\text { tor }\left(\times 10^{-6} \mathrm{daN} /\right. \\
\left.\mathrm{cm}^{2}\right)\end{array}$ & 0.1050 & 1.3 & 0.415 & 1.2 & 1.0 & 0.77 & $1.69-2.1$ \\
\hline $\begin{array}{l}\text { Tensile } \\
\text { strength (daN/ } \\
\text { cm }^{2} \text { ) }\end{array}$ & $100-300$ & $1500-3200$ & $200-600$ & $1500-4500$ & $1200-2200$ & $1400-3800$ & $3000-8000$ \\
\hline
\end{tabular}


bodies and columns, large sculptures, decorations etc.).

Zinc (spelter) is a bluish-white metal, oxidized only on its surface in a thin layer that protects against corrosion. It adheres very well to iron structures, sheets and, as a positive element for corrosion, it is efficiently protects the covered iron (e.g. galvanized sheet) by its own damage. Thus, it is the raw material of many structural decorations (Figure 2.). Excellent stone imitations have been made from bronze-coated castings.

Tin is silver-white, very soft, heavy metal, highly stretchable, hammerable. White tin requires high attention because below $13.2^{\circ} \mathrm{C}$ it becomes grey tin, which is powder (tin plague). It adheres very well to iron structures, sheets (e.g. cast iron plate or white plate) and protects them (as a positive element) from corrosion, as does zinc.

Lead is a bluish grey, heavy soft metal. The surface is oxidized in a thin layer that protects against corrosion and against diluted acids (sulfuric acid, hydrochloric acid), except nitric acid (HNO3). It can be easily stretched at normal temperatures, but it becomes very rigid around its melting point. It is frequently found as plates, wires, pipes, and as insulating materials, as well as contact material at the leaning points of plates, cast iron, stone and wooden pillars.

Iron is silver-white, heavy metal, rusting (corroding) in air, and in the absence of protection, the entire iron structure may be destroyed (Figure 3.). Rusting begins on its surface (a brown oxide-hydroxide layer is formed which is not coherent so it cannot protect the iron piece from further oxidation) and breeding inward can also cause swelling.

Iron can be found mostly as crude iron (white or grey), cast iron (pig-iron), wrought iron (forged iron) or steel in the structure of old buildings.

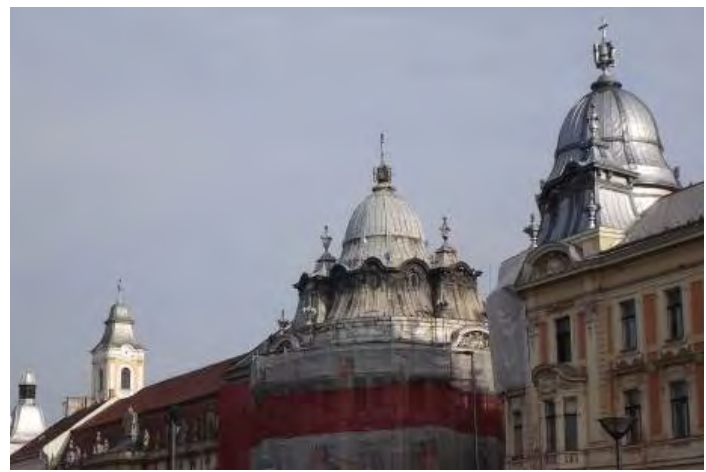

Figure 2. Domes covered with galvanized sheets on the main square of Cluj-Napoca
Crude iron contains 2.3 to $6 \%$ carbon, where carbon may be in two forms (iron carbide in white crude iron, carbon graphite in grey iron). Cast iron is obtained by melting and moulding the crude iron. Cast iron made from white raw iron is hard (cannot be filed, scraped), it is brittle, it cannot be stretched and it is difficult to melt. Old buildings where the bearing structure is made from this material require high attention because of the very high stiffness and the total lack of ductility (deflection is impossible and the structure cannot withstand the sudden shocks caused by earthquakes). Cast iron made from grey crude iron is softer (can be filed, drilled) and melts more easily. The wrought iron has low carbon content (less than $0.2 \%$ ), it is a softer iron which can be welded or forged. The steel has a carbon content of 1.5-2\% (as iron carbide), being suitable for forging and welding.

\section{Conclusions}

Research and knowledge of the properties of metal materials in old buildings not only helps in finding structural defects, but also in formulating proper suggestions to overcome deficiencies. Although the applicable regulations for loadbearing structures vary from time to time, the buildings must have sufficient loadcarrying capacity and durability. The rigidity and durability of all supporting structures depend primarily on the structural material used, so the opinion of the structural construction expert and his provisions for safe and rational use of the building are the only viable route. The expert must examine whether the bearing structure is capable of safely transferring the loads to the ground without noticeable changes in the formal relationships. When calculating stresses, special care must be taken

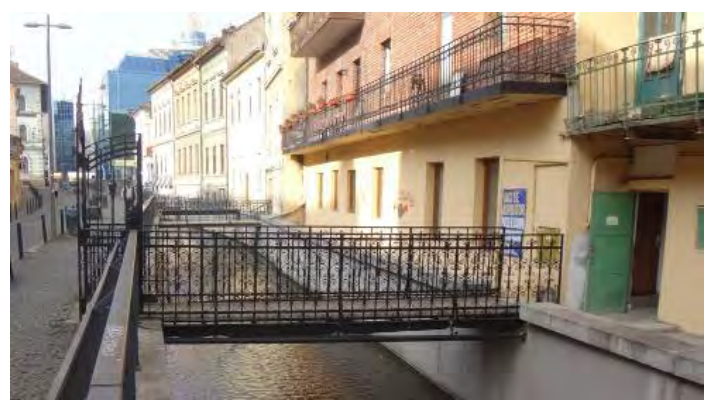

Figure 3. Iron bridge (wrought iron railing and gate, rust eaten steel beam stiffened with a pipe at the bottom) and balconies over the Mill-Channel in Cluj-Napoca 
for the structural parts to not exceed the elasticity boundary. Over the elastic limit the structure is closely related to fatigue failure (it is recommended to use only the half-values of the limit stresses during the calculations in the case of outworn metal structures, due to their age).

Today's design philosophy is based on the "fail safe” principle, allowing local damage but not accepting progressive or complete collapse. This can be achieved only with great simplification in the case of old structures. It is not enough to calculate the strength, deformation and displacement values caused by static and dynamic loads, but is also very important to reduce these loads.

\section{References}

[1] Riederer J.: Kunstwerke chemisch betrachtet. Materialen, Analysen, Altersbestimmung. Springer Verlag, Berlin, Heidelberg, New York, 1981.

[2] Kopenetz L.G.: Gondolatok statikusoknak. Editura Kriterion, Cluj-Napoca, 2006. 